\title{
Investigation and Improvement of Content of Methane in Biogas Generated from Municipal Solid Waste.
}

\author{
Shyamsing Thakur ${ }^{1 *}$, and Rahul Barjibhe ${ }^{2}$ \\ ${ }^{1}$ KBCNMU, Jalgaon, Maharashtra, 425001 India. \\ ${ }^{2}$ SSGBCOET, Bhusawal, Maharashtra, 425203 India.
}

\begin{abstract}
The methane yield and overall biogas generation reduce drastically in the winter and summer season. The Biogas plant operators reported better results with the co-digestion of the municipal solid waste (MSW) with cow dung in changing weather conditions. In this research work the quality and content of methane in biogas generated from biogas plant is improved by co-digestion of MSW, cow dung along with the urine with better carbon to nitrogen $(\mathrm{C} / \mathrm{N})$ Ration. We took number of experiment using different ratio of MSW and additives to improve biogas. Rigorous experimentations concluded that the co-digestion of the MSW, cowdung and urine in the proportion of (55:35:10) with equal amount water in a portable bio digester for anaerobic digestion results into better methane production with maintaining $\mathrm{C} / \mathrm{N}$ ratio and reducing time duration for flammable biogas production.
\end{abstract}

\section{Introduction}

Biogas is clean, concrete, convenient and capable source of energy generation from waste. Biogas has potential to replace conventional fuels e.g. fossil fuels, burnable oils, etc. which are hazardous to the environment .Biogas comprises of many gases constituents generated from the decomposition of organic waste in absence of oxygen. Biogas is generally produced in the container which is called as bio digester. Biodigester is closed container and mixed of organic waste took place to produce biogas. The bio digester is feed with certain organic waste which includes MSW, kitchen waste, agriculture waste and water at some extent. The contain of biogas consist of methane, $\mathrm{CO}_{2}, \mathrm{~N}_{2}$ and $\mathrm{H}_{2} \mathrm{~S}$. At one point some of these gases are harmful and poisonous. Biogas is usually non convention source of energy, eco-friendly, simple and low cost technology. The generation of biogas also produces organic fertilizer. This biogas also used for the generation of electricity, fuel and for healthy cooking.

The process of conversions of biogas from organic waste, agriculture waste, kitchen waste etc through anaerobic digestion is effective from decade. This biogas generation consists mainly of methane. This methane generation is highly effective for rural areas. Biogas also contains certain amount of gases such as $\mathrm{CO}_{2}, \mathrm{H}_{2} \mathrm{~S}, \mathrm{O}_{2}, \mathrm{~N}_{2}$, etc. Thermal, Mechanical and Thermochemical methods of pretreatments are most efficient and effectively implemented as compared to other pretreatment methods. After the implementation of the most efficient thermal, mechanical and thermochemical methods resulted into better methane yield, drop in retention time and improved quality of the manure [1]. Dry MSW contains slow to biodegrade 'lignin' which took longer time to degrade and occupy top level of slurry in the biodigester resulting into scum formation and pretreatments are essential for smooth functioning [2].

Additives should have the nutrition values and enhance biodegradability. It plays vital role in biogas yield and improves metabolic conditions of microbes. The thermophilic digesters are cheaper than mesophilic digesters over a period of time with high initial investments. The Co-digestion means the mixing of multiple feedstocks had best results than single AD digester in terms of nutrition enrichment, less toxicity, simplified implementation, and higher biogas yield. Several pretreatment techniques are available optimization of the current technology is essential [3].

Major problem in biogas generation is larger retention time (30 to 50 days) and less productivity in summer and winter. Use of additive is beneficial but limited due to seasonal availabilities of additives. Implementation of implant pure culture of microbes should be look as future scope in order to taken into account human health and circular economy. Unwontedly research related to high total solid content cowdung was limited to lab scale only. Large scope to implement these on fields conditions of WWTP's [4].

The mixing facilitate co-digestion of more than one substrate and progressively the acculturate the C/N Ratio [7].Optimum mixing ratio of food waste to cowdung $3: 1$ reported highest methane production [9].In order to reduced the contain of this unwanted gases certain additives is use. Cow urine has important $\mathrm{N}$ component and traces of $\mathrm{P}, \mathrm{K}, \mathrm{Ca}$ and $\mathrm{Mg}$ [10]. According to literature survey, it indicates that the addition of substances such as urine could increase the efficiency of

Corresponding author: thakur.shyamsing23@gmail.com 
biogas generation and maintain better content of methane in biogas. Availability of animal urine and its nitrogen rich nature could be beneficial. The animal urine can use as additive with MSW. C/N ratio is moderately higher in urine due to its nitrogen content promising way to enhance the biogas production. Carbon (C) /Nitrogen (N) ratio of 20: 1 to 30:1 is generally maintained. Methane contents were enhanced by the mixing cowdung, food waste and organic portion of MSW when applied in the optimum condition with lesser retention time model of 30 days [6] surprisingly, the optimum combination were not evaluated in the study.

Half of the volatile solid of the cow dung waste is biodegrade and decompose into biogas. The animal urine used as additive is easily avilable from cattle farm. The discharge urine from animal is practically of no used and also polluted the environment. Thus use of urine the environmental pollution would be decreased at quick rate. So, considering the overall situtaion for the experimentation the use of urine in the MSW for anerobic digestion will increases the production of biogas at high rate, reduces the additive cost and so on thus thus experiment was conducted for the effect of MSW with urine for biogas production.

Table1. Biogas Constituents

\begin{tabular}{|l|l|}
\hline Components & $\begin{array}{l}\text { Content } \\
\text { ( Volume of } \\
\text { constituents } ~ \\
\text { Total Volume) }\end{array}$ \\
\hline $\begin{array}{l}\text { Methane } \\
\text { (CH4) }\end{array}$ & $50 \%$ to $60 \%$ \\
\hline $\begin{array}{l}\text { Carbon } \\
\text { Dioxide } \\
\text { (CO2) }\end{array}$ & $35 \%$ to $40 \%$ \\
\hline Water (H2O) & 2 to $7 \%$ \\
\hline $\begin{array}{l}\text { Hydrogen } \\
\text { Sulphide } \\
\text { (H2S) }\end{array}$ & $2 \%$ \\
\hline $\begin{array}{l}\text { Ammonia } \\
\text { (NH3) }\end{array}$ & 0 to $0.05 \%$ \\
\hline Nitrogen & Upto $0.2 \%$ \\
\hline Oxygen & Upto $0.2 \%$ \\
\hline Hydrogen & Upto $0.1 \%$ \\
\hline
\end{tabular}

\section{Material and Methods}

\subsection{Preparations of Feeding Constituents}

MSW (Municipal Solid Waste) was collected from different part of city for mixing in biodigester. For additive purposes, we have selected animal urine and cow dung [9] as it maintains $\mathrm{C} / \mathrm{N}$ ratio after anaerobic digestion and animal urine easily available. Thus, we collected cattle urine from cattle farm nearby to our experimentation location. The properties of the MSW, cowdung and urine are shown in table 2.
Table2. Properties of feeded mixtures and types of the digesters

\begin{tabular}{|l|c|c|c|}
\hline & MSW & $\begin{array}{l}\text { COW } \\
\text { DUNG }\end{array}$ & URINE \\
\hline $\begin{array}{l}\text { VFA } \\
(\mathrm{g} / \mathrm{l})\end{array}$ & 8.9 & 0.2 & $\begin{array}{c}150 \\
\mu \mathrm{mole} / \mathrm{l}\end{array}$ \\
\hline $\begin{array}{l}\mathrm{VS} \\
(\mathrm{g} / \mathrm{l})\end{array}$ & 169.2 & 12.8 & - \\
\hline $\begin{array}{l}\mathrm{COD} \\
(\mathrm{g} / \mathrm{l})\end{array}$ & 13.8 & 158.3 & - \\
\hline $\mathrm{TS}(\mathrm{g} / \mathrm{l})$ & 222.4 & 21.2 & - \\
\hline PH (g/l) & 4.6 & 7.2 & $5.8-6$ \\
\hline $\begin{array}{l}\text { C/N } \\
\text { RATIO }\end{array}$ & 25 & 6 & 17.54 \\
\hline
\end{tabular}

*Traces of P, K, Ca and Mg found in PPM

\subsection{Construction of biodigester}

For experimentation purpose we have prepared a lab scale portatble biodigestor.
i. 20L container.
ii. Ballon for gas storage.
iii. PVC pipie for inlet and outlet.
iv. Connecting tube.
v. Flow control valve

The lab scale portable model was used for the further experimentations.

\subsection{Experimentations}

The experiments were conducted in three different biodigesters as per tests. The biodigester compramises of the 20L container, Ballon for gas storage, PVC pipie for inlet and outlet, Connecting tube and flow control valves.The pressure is mainteained on the top of biodigester by weight. The Biodigster is covered to restrict extrageneous factors like sunlight etc.The flow control valves are used to regulate the flows.The digester temperature kept at aound the $35^{\circ} \mathrm{c}$.

Test 1 : MSW with equal quantity of water.

Test 2 : MSW mixed with cowdung (3:1) and equal amount of water [9].

Test 3 : MSW, Cow dung and urine (55:30:10) with equal amount of water.

Biogas collected in the storage tube,observations were recorded a regular intervals.For formation of biogas at small scale it needs at least 7-8 days. The reading were taken upto 25 to 30 days of feeding when biodigeter 
attains the stabillity [5].The tests were rigoursly repeated to confirm the results.

\subsection{Analytical Methods}

The PH, TS, COD, VFA and TVS were determined by APHA 2005 standards. Gas chromatograph (MethodTCD) used to measure quality of the biogas.

\section{Results and Discussion}

The Test 2 and Test 3 concluded that the biogas was collected in the storage tube at faster rate as compared to ideal rate of biogas formation Test 1 of mono-digestion. The time required for formation of biogas (test 2 and test 3) was reduced as compared to standard time required for biogas formation without additives (test 1). The collected biogas was feed into gas chromatography (Method TCD) machine and the outputs were recorded. Biogas consists of methane, nitrogen, carbon dioxide, hydrogen sulphite.

\subsection{Effect of co-digestion on the production of the Biogas}

The Experimentations were done with different Codigestion and mono-digestion the Bio gas generation were evaluated.

Test run 1 (MSW)

Test run 2 (MSW+ COWDUNG)

Test run 3 (MSW+COWDUNG+URINE)

Above tests gave peak biogas production and burnable biogas at 25 days, 23 days and 21 days respectively. The Methane yield and Quality is found out to be best in test run 3. Urine contains the nitrogen which is favorable for the bacteria growth. The codigestion with cowdung and urine enhances the concentration of soluble organic constituents which in turns reduces the time required for hydrolysis stage of Methanogenesis process and results into better biogas production.

\subsection{Effect of co-digestion on Contents of Methane in produced biogas.}

The Methane contents were experimentally tested on weekly basis by Gas Chromatographs (Method TCD). The Experimentations were done to evaluate methane contents in biogas generated from different compositions.

The Test run 1 (MSW), Test run 2 (MSW+ COWDUNG) and Test run 3 (MSW+COWDUNG+URINE) gave directly proportional biogas production along biodigestion time in weeks. The Methane yield and Quality is found out to be best in test run 3.

The co-digestion with Cowdung and urine breed the methanogenic bacteria and developed the better culture of bacteria which results into improved methane contents in generated biogas.

\subsection{Effect of co-digestion on The pH}

The $\mathrm{pH}$ is most drubbing factor for the growth and survival of microbes during AD methanogenesis. The drastic $\mathrm{pH}$ reduction inhibits the methane formation. The $\mathrm{pH}$ is a function of the Volatile Fatty Acid and carbon dioxide generations. Stable maximum $\mathrm{pH}$ obtained during co-digestion of the cow dung and MSW is 6.7 to 7.2 similar to the study of Kumar Awasthi [6]. In all the tests with different additives the digester reaches to the stable $\mathrm{pH}$ that means the digestion is neutral at the end of the experimentations. The codigestion helps to stabilize the $\mathrm{PH}$ which is essential for bacterial growth and hence the biogas production.

\section{Conclusions}

The Test run 1 (MSW), Test run 2 (MSW+ COWDUNG) and Test run 3 (MSW+COWDUNG+URINE) gave peak biogas production and burnable biogas at the 25 days, 23 days and 21 days Respectively. Methane yield is found out to be best in test run 3 due to the better $\mathrm{C} / \mathrm{N}$ ratio maintained. Stable maximum $\mathrm{pH}$ obtained during codigestion of the cow dung and MSW and mono digestion is 6.7 to 7.2.The Test 2 and Test 3 concluded that the biogas was collected in the storage tube at faster rate as compared to ideal rate of biogas formation Test 1 of mono-digestion. The retention time required for formation of burnable biogas (test 2 and test 3) was reduced as compared to standard time required for biogas formation without additives (test1). The maximum methane content in biogas obtained from the co-digestion of MSW, cowdung and urine was found out be around $68 \%$. The upgradation of biogas purification and compressing it to CNG technology development at affordable cost is biggest challenge for future.

\section{Acknowledgement}

Special thanks to the Research and Development department of Mailhem Ikos Pvt. Ltd. for providing the access to the testing lab along with the guidance and mentoring during tenure of project. 


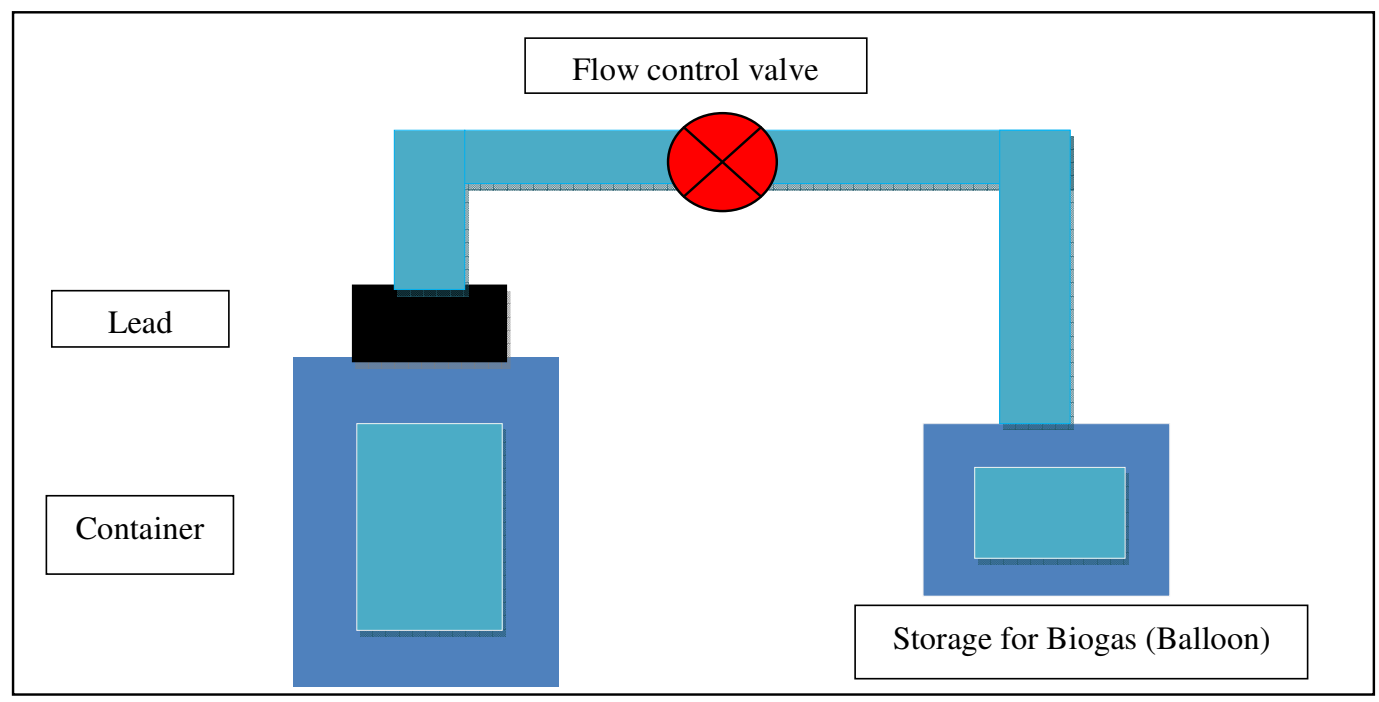

Fig.1. Construction of bio-digester

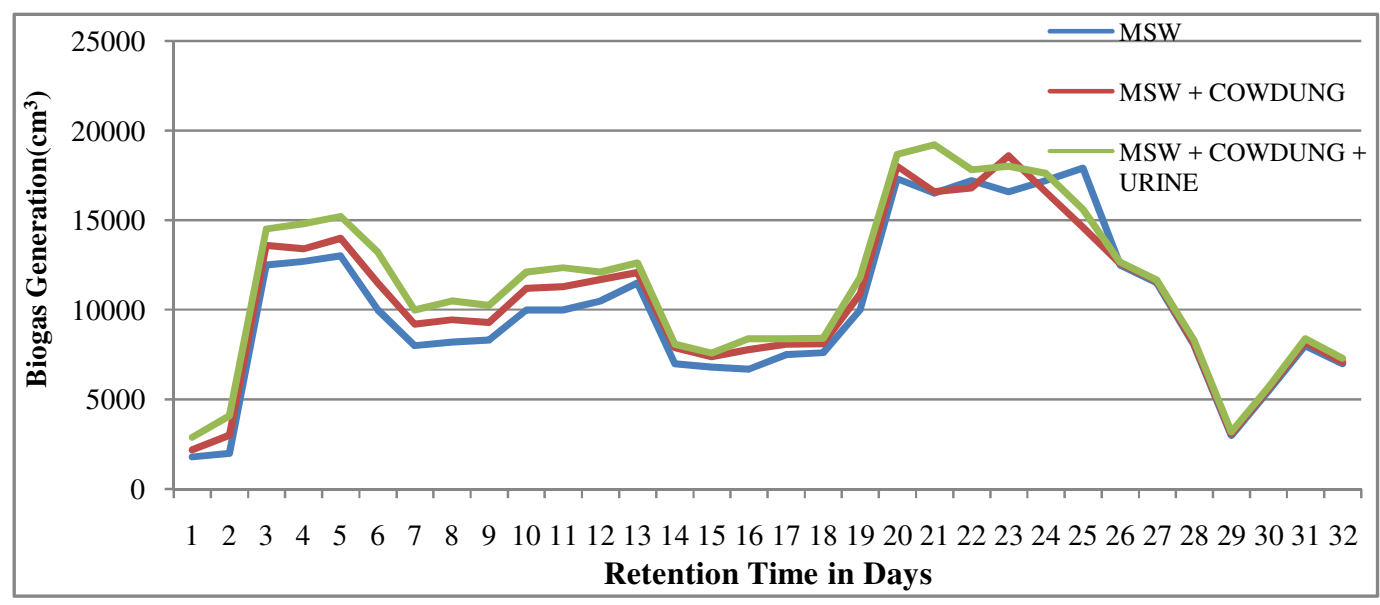

Fig.2. Biogas Generation $\left(\mathrm{CM}^{3}\right)$ Vs Retention Time (Days)

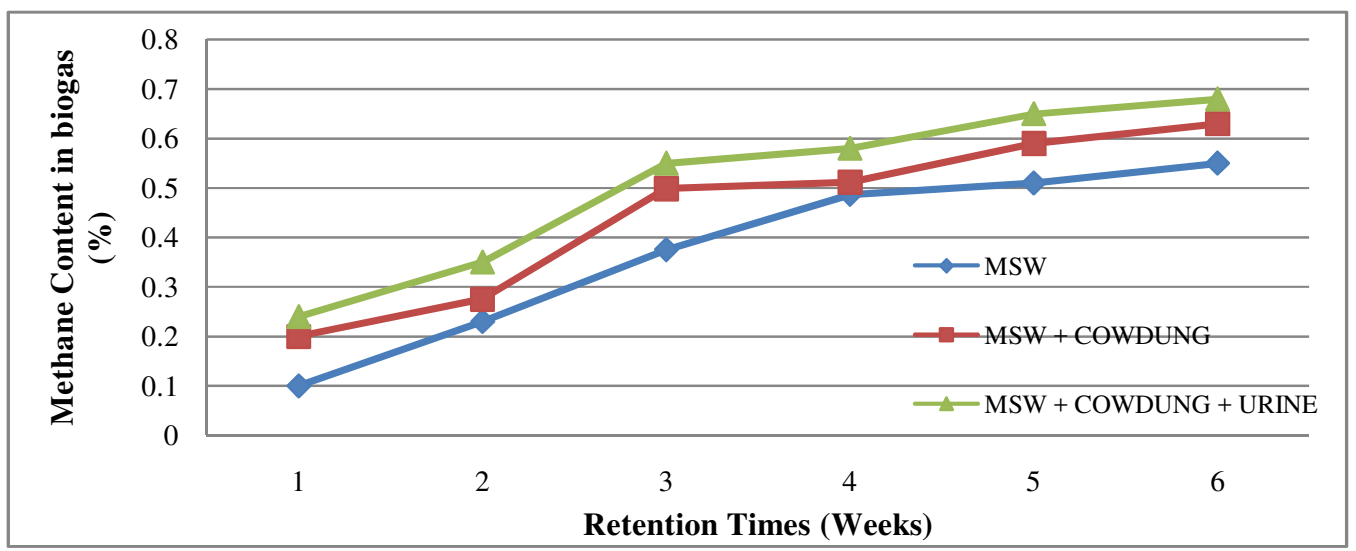

Fig.3. Methane Content (\% ) Vs Retention Time (Weeks) 


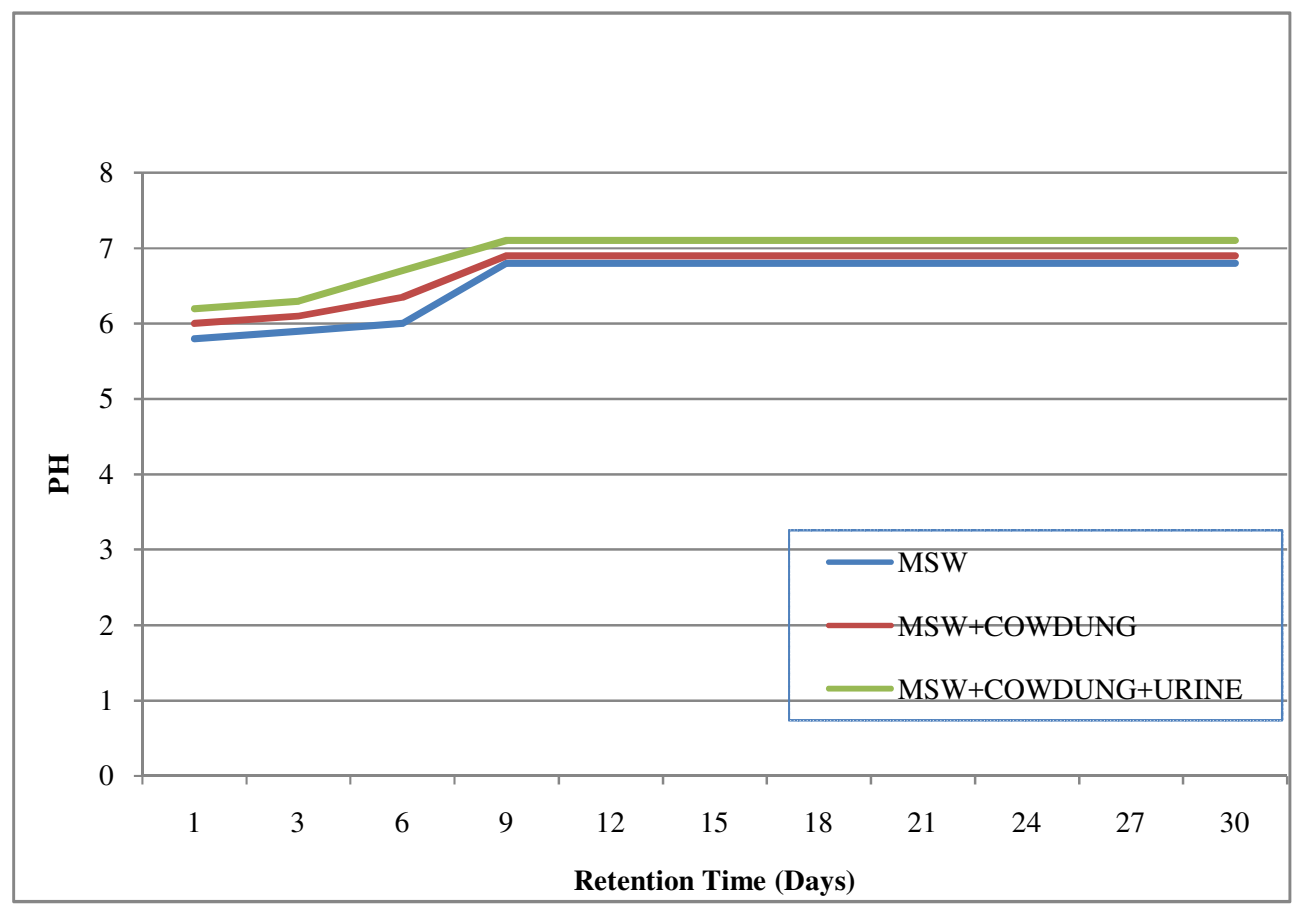

Fig.4. PH Variation Vs Retention time

\section{References}

1. S. Jain, I. T. Wolf, J. Lee, Y. W. Tong, Renewable and Sustainable Energy Reviews, 52, 142-154 (2015).

2. M. Krishania, V.K. Vijay, R. Chandra, Energy, 57, 359367 (2013)

3. C. Mao, Y. Feng, X. Wang, G. Ren, Renewable and Sustainable Energy Reviews, 45, 540-555 (2015).

4. Y., S., T.R Sreekrishnan, S. Kohli \& V. Rana, Bioresource technology, 95, 1-10 (2004).

5. A.K. Jha, Li, J., Ban, Q., Zhang, L., Zhao, B., Pak. J. Biol. Sci. 15, 1111-1118 (2012).

6. S.K. Awasthi, R.Joshi, H. Dhar, S.Verma, M.K. Awasthi, S. Varjani, S.Sarsaiya, Z.Zhang, S.Kumar, Bioresource Technology, (2018).

7. R.Zhang, R.M .Mashad, K.Hartman, F.Wang, G.Liu, C.Choate, P.Gamble, Bioresour. Technol. 98, 929-935 (2007).

8. J. K. C. L. Zhang, J. Lee, C.H. Wang, Y. Dai, Y.W.Tong, Scientific Reports, 7, 1269 (2017),

9. R. Li , S. Chen \& X. Li, Part A: Recovery, Utilization, and Environmental Effects, 31, 1848-1856 (2009).

10. W. H. M. Saunders", New Zealand Jour. of Agri. Research, 25, 61-68, (1982).

11. C. Okeh, C. O. Onwosi, F. John, C. Odibo, Renewable Energy, 62,204-208, (2014).
12. M.O.L. Yusuf, N. L. Ify, Biomass and Bioenergy, 35, 1345-1351, (2011).

13. S. Zhou, Y. Zhang, Y. Dong, Energy, 46, 644-648 (2012).

14. Stromberg, Sten, M. Nistor, and J. Liu., Waste Management, 2014.

15. C. Ma, J. Liu, M.Ye, L. Zou, G. Qian, Y.Y.Li, Renewable and Sustainable Energy Reviews, 2018

16. J. Yang, D. Wang, Z. Luo, W. Zeng, Waste Management, 2019.

17. D. barik, S. Murugan, Waste and Biomass Valorization, 2015.

18. S. Achinas, Y. Li, V. Achinas, G. Jan W. Euverink, Sustainable Environment Research, 28, 240-246 (2018). 